8. HAMILTON, J.D.; LEACH, W.B.: "Adenocarcinoma arising in divertículum of female urethra". Arch. Path., 51: 90,1951 .

9. EBISUNO, S.; MIYAI, M.; NAGAREDA, T.: "Clear cell adenocarcinoma of the female urethra showing positive staining with antibodies to prostate-specific antigen and prostatic acid phosphatase". Urology, 45: 682, 1995.

10. KAWANO, K.; YANO, M.; KITAHARA, S. y cols.: "Clear cell adenocarcinoma of the female showing strong inmunostaining for prostate-especific antigen". BJU Int., 87: 412, 2001.

*11. DREW, P.A.; MURPHY, W.M.; CIVANTOS, F. y cols.: "The histogenesis of clear cell adenocarcinoma of the lower urinary tract: case series and review of the literature". Hum. Pathol., 27: 248, 1996.

12. MAIER, U.; DORFINGER, K.; SUSANI, M.: "Clear cell adenocarcinoma of the female urethra". J. Urol., 160: 492, 1998.

*13. HERRERO, J.A.; LLORENTE, C.; SÁNCHEZ, E. y cols.: "Tumores de uretra femenina: dificultad en el diagnóstico precoz”. Arch. Esp. Urol., 47: 677, 1994.
Casos Clínicos

Arch. Esp. Urol., 58, $7(682-684), 2005$

\section{FÍSTULA PANCREÁTICA POST NEFRECTOMÍA IZQUIERDA}

Ángel M anuel Tundidor Bermúdez

Servicio de Urología,

Hospital G eneral Docente "G uillermo Domínguez", Puerto Padre, Las Tunas, Cuba.

Resumen.- O BJETIVO S: Informar nuestra morbilidad en cuanto a fístulas pancreáticas post nefrectomía izquierda, y llamar la atención sobre esta complicación infrecuente.

M ÉTO DO S: Se revisaron las historias clínicas de los tres casos de fístula pancreática post nefrectomía izquierda acaecidos en nuestra institución en el período 1983. 2004.

RESULTADO S: Todos los pacientes fueron del sexo masculino, con edad promedio de 51 años. La nefrectomía estuvo determinada por adenocarcinoma renal, absceso renal, o pionefrosis. En los tres casos la vía de abordaje fue la incisión clásica de Israel, con apertura accidental del peritoneo. A parecieron signos inflama torios en la herida como promedio a los 3 días de postoperatorio, y eliminación de jugo pancreático por el drenaje 4 días después de la operación. El tratamiento consistió en suspensión de la vía oral durante 7 días, hidratación por venoclisis, y administración de atropina y de antibióticos de a mplio espectro. La fuga de jugo pancreático tuvo una duración promedio de 8 días.

Ángel M. Tundidor Bermúdez.

C alle 5 a $\mathrm{N} \cong 22$, Reparto M édico, 77210 Puerto Padre, Las Tunas. (Cuba). cmicm@villazul. Itu.sld.cu

Trabajo recibido: 11 de enero 2005 
CON CLUSIO NES: La lesión de la cola del páncreas es una posible complicación de la nefrectomía izquierda, dadas las estrechas relaciones anatómicas entre ambos órganos, que pueden estar especialmente alteradas por la enfermedad tumoral o inflamatoria del riñón. De no reconocerse, puede conducir a la formación de una fístula pancreática, con cuyo diagnóstico y tratamiento debe estar familiarizado el urólogo.

Palabras dave: Fístula pancreática. N efrectomía izquierda.

Summary- O BJEC TIVES: TO report our experience with pancreatic fistula after left nephrectomy to point out this unfrequent complication.

METHODS: We perform a chart review of 3 cases of pancreatic fistula after left nephrectomy experienced in our institution between 1983-2004.

RESULTS: All patients were males, with an average age of 51 years. Indications for nephrectomy were renal cell carcinoma, renal abscess and pyonephrosis. Classic Israel incision was the surgical approach in all three cases, with accidental opening of the peritoneum. W ound inflammatory signs appeared on third postoperative day, drainage of pancreatic juice on postoperative day 4. Treatment consisted on N PO 7 days, and intravenous hydration, atropin and wide spectrum antibiotics. Mean duration of pancreatic juice drainage was 8 days.

CON CLUSION S: Pancreatic tail injury is a possible complication of left nephrectomy due to the close anatomical vicinity of both organs, that may be altered by tumoral or infla mmatory disease of the kidney. If not recognized, it may lead to a pancreatic fistula, the diagnosis and treatment of which should be known by the urologist.

Keywords: Pancreatic fistula. Left nephrectomy.

\section{INTRODUCCIÓN}

Entre las complicaciones infrecuentes de la nefrectomía izquierda se señala la lesión de la cola del páncreas. Esta puede ser advertida y tratada durante el acto quirúrgico; de lo contrario, dará lugar a la formación de un pseudoquiste 0 de una fístula pancreática (1). El urólogo debe estar familiarizado con el diagnóstico y el tratamiento de estas raras complicaciones.
Presentamos tres casos de fístula pancreática post nefrectomía izquierda.

\section{MATERIAL Y MÉTODOS}

Se revisaron las historias clínicas de los tres casos de fístula pancreática post nefrectomía izquierda acaecidos en nuestra institución en el período 1983-2004.

\section{RESULTADOS}

Todos los pacientes fueron del sexo masculino, con edad promedio de 51 años. La nefrectomía estuvo determinada por adenocarcinoma renal, absceso renal, o pionefrosis. En los tres casos la vía de abordaje fue la incisión clásica de Israel, con apertura accidental del peritoneo. Aparecieron signos inflamatorios en la herida como promedio a los 3 días de postoperatorio, y eliminación de jugo pancreático por el drenaje 4 días después de la operación.

El tratamiento consistió en suspensión de la vía oral durante 7 días, hidratación por venoclisis, y administración de atropina y de antibióticos de amplio espectro. La fuga de jugo pancreático tuvo una duración promedio de 8 días. (Tabla I)

\section{DISCUSIÓN}

La lesión de la cola del páncreas es una posible complicación de la nefrectomía izquierda, dadas las estrechas relaciones anatómicas entre ambos órganos, que pueden estar especialmente alteradas por la enfermedad tumoral o inflamatoria del riñón $(1,2)$, como en los tres casos que presentamos, en los que ocurrió además apertura accidental del peritoneo, debida a la presencia de adherencias durante la disección renal.

En ninguno de estos casos la lesión del páncreas fue identificada durante el acto quirúrgico, por lo que dio lugar a la fuga de jugo pancreático por el drenaje de la celda renal. Usualmente el jugo pancreático puede reconocerse por su coloración anaranjada y su consistencia viscosa, su $\mathrm{pH}$ francamente alcalino, y sobre todo por su contenido de amilasa $(2,3)$.

Las fístulas pancreáticas suelen curar con medidas conservadoras, tales como la suspensión de la vía oral, y la administración de anticolinérgicos como la atropina y antibióticos de amplio espectro $(2,3)$. 
TABLA I.

\begin{tabular}{|c|c|c|c|}
\hline Edad (Años) & $\begin{array}{c}\text { Caso \# } 1 \\
45\end{array}$ & $\begin{array}{c}\text { Caso \# } 2 \\
33\end{array}$ & $\begin{array}{c}\text { Caso \# } 3 \\
74 \\
\end{array}$ \\
\hline Sexo & $M$ & $M$ & $M$ \\
\hline $\begin{array}{c}\text { Enfermedad } \\
\text { de base }\end{array}$ & $\begin{array}{c}\text { Absceso } \\
\text { renal }\end{array}$ & Pionefrosis & $\begin{array}{c}\text { A denocarcinoma } \\
\text { renal }\end{array}$ \\
\hline $\begin{array}{c}\text { Vía de abordaje } \\
\text { para la } \\
\text { nefrectomía }\end{array}$ & $\begin{array}{c}\text { Lumbotomía de } \\
\text { Israel (extraperitoneal) }\end{array}$ & $\begin{array}{c}\text { Lumbotomía de } \\
\text { Israel (extraperitoneal) }\end{array}$ & $\begin{array}{c}\text { Lumbotomía de } \\
\text { Israel (extraperitoneal) }\end{array}$ \\
\hline $\begin{array}{l}\text { Accidentes } \\
\text { operatorios }\end{array}$ & A pertura del peritoneo & A pertura del peritoneo & A pertura del peritoneo \\
\hline $\begin{array}{c}\text { A parición de signos } \\
\text { inflamatorios } \\
\text { en la herida } \\
\text { (Días de postoperatorio) }\end{array}$ & 2 & 3 & 3 \\
\hline $\begin{array}{l}\text { Primera evidencia, por } \\
\text { inspección, de fuga de } \\
\text { jugo pancreático } \\
\text { (Días de postoperatorio) }\end{array}$ & 2 & 7 & 4 \\
\hline $\begin{array}{l}\text { Cantidad inicial } \\
\text { (mL24 horas) }\end{array}$ & 300 & 25 & 15 \\
\hline pH de la secreción & 10 & 10 & 8 \\
\hline $\begin{array}{c}\text { A milasa en la secreción } \\
\text { (Uds.) }\end{array}$ & 256 & No determinada & No determinada \\
\hline $\begin{array}{c}\text { Duración de la fuga de } \\
\text { jugo } \\
\text { Pancreático } \\
\text { (Días) }\end{array}$ & 8 & 13 & 4 \\
\hline
\end{tabular}

Los casos aquí reportados, en los que la fuga de jugo pancreático nunca superó los $300 \mathrm{~mL}$ en 24 horas, no requirieron medidas adicionales. En casos más severos se ha indicado alimentación parenteral total y administración de somatostatina intravenosa $(1,3)$.

La duración de la fuga de jugo pancreático en el presente estudio (4-13 días, promedio: 8 días) puede considerarse breve en comparación con la de los dos casos reportados por Masuda y cols. (33 y 55 días) (2).

\section{BIBUOGRAFIA y LECTURAS RECOMENDADAS (*lectura de interés y **lectura fundamental)}

*1. HERNÁNDEZ FERNÁNDEZ, C.; MONCADA IRIBARREN, I.; ESCRIBANO PATIÑO, G. y cols.: "Manejo de lesiones pancreáticas en cirugía urológica". Actas Urol. Esp., 16: 223,1992.

*2. MASUDA, F.; HISHINUMA, H.; IHZUKA, N.: "Pancreatic cutaneous fistula as a complication of left nephrectomy". Hinyokika Kiyo., 31: 1619, 1985.

3. SCHWARTZ, S.I.; SHIRES, G.T.; SPENCER, F.C. (Ed.): "Principios de Cirugía". $6^{a}$ edición. Vol 1. Pp. 216 y 494. Interamericana, México D.F., 1995. 